\title{
La ética profesional de profesores de educación media superior. La visión estudiantil
}

\section{Professional ethics of upper secondary school teachers: the students' perspective}

\author{
DOI: https://doi.org/10.32870/dse.v0i22.710
}

\author{
Judith Pérez-Castro* \\ Juan Manuel Piña Osorio**
}

\begin{abstract}
Resumen
Nuestro objetivo en este artículo es analizar las conductas no éticas de los profesores desde las opiniones de un grupo de estudiantes de educación media superior. La perspectiva teórica es la ética profesional docente y, específicamente, distinguimos entre las conductas éticamente cuestionables y éticamente inaceptables. La investigación fue de tipo cualitativo y para el trabajo empírico recurrimos a la estrategia de grupos focales, los cuales se realizaron en tres planteles de la Ciudad de México, de distintas modalidades educativas: un bachillerato general y dos bachilleratos universitarios.

Los grupos focales nos permitieron identificar cinco comportamientos éticamente cuestionables en los profesores: la desactualización de los métodos de enseñanza, la poca capacidad de diálogo, el desinterés por el aprendizaje de los alumnos, la imposición de temas y la indiferencia ante situaciones de violencia. Con respecto a los éticamente inaceptables, los alumnos señalaron tres: el acoso sexual, las actitudes discriminatorias por la situación económica y por la apariencia física.
\end{abstract}

Palabras clave: Ética profesional - conductas no éticas - educación media superior - profesores - estudiantes.

\begin{abstract}
Our objective in this paper is to analyze some teachers' unethical behaviors, based on the opinion of a group of students from upper secondary education. Our theoretical perspective is that of the professional teaching ethics; specifically, we distinguish between ethically questionable behaviors and ethically unacceptable ones. The research was of a qualitative type, and for our empirical work we used a focus group strategy in three schools of different educational modalities in Mexico City, one of them a general high school and the other two college-oriented high schools.
\end{abstract}

* Doctora en Ciencia Social. Miembro del Sistema Nacional de Investigadores, nivel 2. Investigadora titular "A". Líneas de investigación: equidad e inclusión educativa, ética y valores profesionales, políticas educativas en la educación superior. Instituto de Investigaciones sobre la Universidad y la Educación (IISUE)-UNAM. México. pkjudith33@yahoo.com.mx

** Doctor en Pedagogía. Miembro del Sistema Nacional de Investigadores, nivel 2. Investigador titular "C". Líneas de investigación: teoría de las representaciones sociales en educación y ciudadanía en estudiantes de educación superior. Instituto de Investigaciones sobre la Universidad y la Educación (IISUE)-UNAM. México. jmpo@unam.mx 
Based on the information gathered through the focus groups, we identified five ethically questionable behaviors of teachers: the use of outdated teaching methods, poor dialogue skills, lack of interest in students' learning, imposition of topics for written assignments, and disregard towards situations involving violence. As for the ethically unacceptable behavior, the students pointed to sexual harassment and discriminatory attitudes on the grounds of their economic status and/or physical appearance.

Key words: Professional ethics - unethical behavior - upper secondary education - teachers - students.

\section{Introducción}

El maestro ha sido una figura importante a lo largo de la historia de la humanidad porque tiene en sus manos la formación de las generaciones jóvenes para la vida adulta, con el propósito de desarrollar en ellos "los estados físicos, intelectuales y morales que exigen tanto la sociedad política en su conjunto como el medio ambiente específico al que está especialmente destinado" (Durkheim, 2000: 60). Por eso, la pregunta sobre el buen profesor es un asunto recurrente en los actores educativos. Los padres de familia indagan sobre los mejores docentes de la escuela, los maestros a su vez valoran a ciertos colegas como los mejores y los directivos también quieren tener a los mejores educadores como garantía de que su institución es un modelo de enseñanza. Los criterios para calificar al buen y al mal docente difieren fácilmente debido a que los intereses de cada emisor son distintos. En los estudiantes, por ejemplo, la clasificación de un buen o mal profesional de la enseñanza se basa en sus experiencias vividas. La experiencia es un acontecimiento exterior al sujeto, el cual irremediablemente se queda en él (Larrosa, 2006). Es un acontecimiento que pasa:

[...] ante mí o frente a mí, sino a mí, es decir, en mí. La experiencia supone, ya lo he dicho, un acontecimiento externo a mí. Pero el lugar de la experiencia soy yo. Es en mí (o en mis palabras, o en mis ideas, o en mis representaciones, o en mis sentimientos, o en mis proyectos, o en mis intenciones, o en mi saber, o en mi poder, o en mi voluntad) donde se da la experiencia, donde la experiencia tiene lugar" (Larrosa, 2006: 45).

La experiencia está acotada a una persona, es una vivencia individual que modifica a quien la experimenta; altera sus ideas, creencias y trabajo, porque lo transforma. Responde a situaciones externas que afectan directamente a cada persona. La experiencia puede ser agradable o desagradable, pero, en cualquier caso, deja huella en cada cual. Lo mismo ocurre con los estudiantes, algunas de sus experiencias tienen un sentido formativo, de enriquecimiento como ciudadano o como futuro profesional, mientras que otras pueden ser negativas, desagradables, pero ambas se conservan en cada uno de ellos. 
En este escenario todo puede ser válido para quienes lo expresan, porque responde a sus experiencias; por ejemplo, los padres y directivos tienen sus propias ideas de lo que es un buen docente, pero estas ideas no necesariamente coinciden con lo que necesita el alumnado o con lo que es más recomendable para su formación. Lo anterior, en el campo de la educación ha hecho cada vez más necesario investigar sobre las percepciones, creencias, concepciones o representaciones de aquello que se considera un "profesor modelo", y al mismo tiempo analizar el tipo de docencia que predomina en los espacios educativos. Las preguntas que han orientado estas indagaciones han sido: ¿qué transmite el maestro en sus clases, solo los conocimientos y habilidades para el mercado laboral o enseña algo más? (Durkheim, 2000) y ¿qué papel cumple en la formación en valores de las generaciones jóvenes?

Nuestro propósito en este artículo es acercarnos a la ética profesional del maestro de educación media superior desde la perspectiva de los estudiantes. Sostenemos que los valores se transmiten en las clases y en la vida escolar independientemente de la conciencia que los actores educativos tengan de ello, a través de la reiteración de disposiciones y prácticas específicas, es decir, a través del currículum oculto (Díaz, 2006; Jackson, 1992).

El artículo está organizado en cinco apartados. Iniciamos con un recorrido por las investigaciones acerca del buen docente, especialmente analizamos al sujeto que emite o valora el concepto empleado por los autores, la metodología diseñada y los resultados. Continuamos con la discusión sobre la ética profesional docente y las conductas no éticas, tanto las inaceptables como las cuestionables. En tercer lugar, exponemos el procedimiento metodológico que permitió obtener información de primera mano en un grupo de estudiantes de tres bachilleratos de la Ciudad de México. En el cuarto, mostramos los resultados con base en dos dimensiones: conductas éticamente cuestionables y éticamente inaceptables en el profesor. Finalmente, cerramos con algunas consideraciones generales en torno a los temas tratados.

\section{¿Qué se entiende por buen profesor?}

Antes de entrar al tema central de nuestro artículo, consideramos pertinente analizar lo que significa ser "buen profesor" ya que en la producción académica aparecen diversos rasgos y prácticas directamente relacionados con la actuación ético-profesional. Algunos trabajos se interesan por definir los atributos indispensables que requiere el docente contemporáneo. Para Angulo (2012), el docente es un intelectual orgánico comprometido con su práctica diaria y con sus colegas, de manera que entre todos puedan comprender el contexto histórico-social que los rodea y se comprometan con la transformación social. De ello se colige que el buen maestro debe ser un intelectual crítico, capaz de analizar el momento en el que vive y consagrarse a la búsqueda de la justicia social.

Otros autores (Casillas, 2006; Chávez, 2019) ven al profesor como la pieza clave en la enseñanza, él es el "catedrático" que transmite contenidos, además de escuchar y auxiliar a los 
estudiantes. El trabajo de estos autores se centra en la eficacia de la enseñanza, por lo que un docente puede considerarse "bueno" si domina los contenidos disciplinarios y la didáctica. Asimismo, debe mantenerse en contacto con los alumnos para apoyarlos tanto en sus problemas escolares como afectivos. Cercanos a esta postura están algunos estudios realizados con formadores de maestros en México. En dos investigaciones cuyo interés fue conocer las representaciones sociales que los profesores de escuelas normales tienen sobre su quehacer, se reportó que el atributo más valorado fue poseer conocimientos sólidos para garantizar el aprendizaje de los estudiantes, así como para mantener el control del grupo (Gutiérrez, 2012; Lozano, 2016). Otros rasgos destacados fueron: el compromiso para escuchar las dificultades de los alumnos, académicas o personales, ser empático y comprenderlos cuando no entendían algo o cuando expresaban sus puntos de vista.

En contraste, están quienes sostienen que lo relevante en la práctica docente es el manejo de la técnica adecuada para recrear los contenidos, hacer que los estudiantes participen activamente en sus aprendizajes, ayudarlos a construir su propio conocimiento y a desarrollar su autonomía (Mas, 2012). También se encuentran aquellas investigaciones que asumen la importancia de ciertos indicadores para evaluar los perfiles docentes, de manera que quienes obtienen los puntajes más altos son considerados excelentes (Navia, Hirsch, 2015); mientras que otras buscan evaluar las competencias del profesor, porque parten del supuesto de que solo quien las posee puede fomentarlas en el estudiantado (Mas, 2012; Hamer, 2015). En ambos casos, los equipos de investigación aplicaron sendos instrumentos con preguntas cerradas, para que los estudiantes señalaran las características que llevan a la excelencia, o bien, las habilidades y competencias más relevantes.

Otros trabajos apelan a las creencias sobre los profesores ejemplares (Cortez, Fuentes, ViIlablanca, Guzmán, 2013). Para seleccionarlos se partió de la opinión de los miembros de la comunidad universitaria. La hipótesis era que los alumnos seleccionarían a los que tuvieran una larga carrera docente, es decir, a los profesores experimentados. Sin embargo, las respuestas se inclinaron por aquellos con menos trayectoria. El criterio que tuvo mayor peso fue el buen trato, es decir, los maestros que eran empáticos con los estudiantes. En esta misma línea de la percepción de los sujetos se encuentra la investigación de Caballero-Montañez y Sime-Poma (2016) sobre las imágenes del buen o buena docente en egresados del nivel secundaria que en ese momento cursaban los estudios superiores. Se solicitó a los participantes que indicaran quiénes habían sido los docentes que los habían "marcado", tanto por sus conocimientos como por la influencia en su trayectoria académica posterior. Los resultados demostraron que el tiempo no borra esta huella, porque los alumnos recordaban tanto los contenidos como las numerosas vivencias desplegadas dentro y fuera del salón de clase. Esta influencia fue posible por el compromiso del profesor con su quehacer, por su dedicación en la tarea de enseñar, por el manejo del contenido y de las técnicas de enseñanza, así como por el respeto al estudiantado.

Diálo@os sobre Educación año 12 | número 23 | julio-diciembre 2021 | ISSN 2007-2171 
Una investigación importante fue la realizada por Navia (2019), quien se propuso caracterizar a los mejores profesores de instituciones formadoras de maestros a partir de la identificación de ciertas categorías teóricas y aproximaciones metodológicas. Se encontraron distintos tipos de análisis, algunos eran evaluaciones sobre el quehacer del maestro y otros buscaban acercarse al buen ejercicio de su profesión. Uno de los atributos más importantes señalados por educandos y colegas, fue que los docentes memorables o auténticos promovían aprendizajes sostenidos en el estudiantado, los cuales influían en su vida personal y profesional. Otro aspecto a destacar es que, en los estudios revisados por la autora, la figura del buen profesor se vinculó con su actuación ética y la forma en que esta se transmitía a los estudiantes, por lo que se concluye que: "la excelencia del profesorado está necesariamente articulada con el ejercicio de la profesión desde una perspectiva ética." (Navia 2019: 181).

La dimensión ética de la docencia es una veta que merece explorarse, porque esta tiene como bien intrínseco contribuir a la formación de profesionales y ciudadanos, lo que requiere de un ethos, de normas que orienten a los profesores en su trabajo diario con los estudiantes. Lo mismo en el nivel básico que en el superior, los maestros interactúan con los alumnos, y en este proceso transmiten conocimientos, enseñan habilidades y forman en valores y actitudes para la escuela, el trabajo y otros ámbitos de la vida. Todo esto nos conduce necesariamente a reflexionar sobre la ética de las profesiones y, de manera particular, sobre la ética de la profesión docente.

\section{Ética docente y comportamientos no éticos}

Hablar de ética profesional no significa necesariamente que los sujetos actúen conforme a ella. Esta puede permanecer invisible en la vida cotidiana, la rutina y la particularidad social, actuando como un referente para la acción. Como hemos dicho, los maestros no solo transmiten contenidos disciplinarios, sino también saberes éticos; para ello, es fundamental que sepan "integrar las expectativas legítimas de otras profesiones y sectores sociales, con especial referencia a las exigencias y demandas legítimas de los beneficiarios directos de la profesión, que en el caso de la enseñanza son los alumnos y sus padres" (Martínez, 2010: 44).

Este proceso exige la participación de todos los miembros de la profesión docente, así como de otros campos profesionales. Es decir, no es una tarea aislada sino un esfuerzo colectivo donde la comunidad establece las normas que deben ser asumidas y respetadas por todos sus integrantes. Esto permite construir un "sentido de pertenencia" o de identidad con la profesión, con su ethos y con el grupo de colegas, y al mismo tiempo coadyuva a que el profesional haga su trabajo pensando en el bien, tanto de los otros como de la sociedad a la que pertenece.

De acuerdo con Hortal (2000), la docencia posee varias cualidades que la convierten en una profesión, entre ellas: que ofrece un servicio a la sociedad porque se encarga de la educación de las generaciones jóvenes; que constituye un medio de subsistencia para quienes la ejercen; los 
docentes pasan por un proceso de formación previo y además están certificados; y pertenecen a un colectivo organizado en academias, cuerpos docentes, colegio de profesores, etcétera. Todos los profesionales, ya sean médicos, ingenieros, administradores, oftalmólogos, abogados, historiadores, psicólogos o profesores, "aumentan la vida" (Hortal, 2000: 60) a través de su labor, por ejemplo, los humanistas le proporcionan sentido y belleza, los médicos quitan dolores y enfermedades, los abogados resuelven problemas jurídicos, y así sucesivamente.

Los docentes contribuyen a hacer la vida más humana por medio de los principios de beneficencia, autonomía y justicia (Hortal, 2000). El primero conlleva "saber enseñar" y "saber hacerse entender", es decir, hacer que los estudiantes aprendan. La enseñanza no solo beneficia moralmente al estudiante sino también al maestro, por lo que este último debe ayudarlo a ser un buen alumno y a ampliar sus horizontes. La autonomía, por su parte, establece los límites del trabajo y orienta al docente para que no caiga en la tentación del paternalismo o el autoritarismo, ni para que utilice su posición para hacer proselitismo ideológico, adoctrinar o infundir sus convicciones personales (Hortal, 2000). Finalmente, la justicia compromete al profesor a contribuir a la distribución de los bienes sociales, en este caso el conocimiento, y hacer bien aquello que se relaciona directamente con su profesión. Este principio implica además que el maestro contribuya al logro de la justicia social, porque, aunque él por sí solo no puede enfrentar los múltiples problemas que aquejan a sus alumnos, "tampoco pueden ignorar ni desentenderse de si lo que hace contribuye o no a generar condiciones sociales más justas en las que haya un lugar digno para todos y cada uno" (Hortal, 2000: 67).

A la par de estos principios, el trabajo docente está acotado por las normas y contextos institucionales en donde se ejerce, dado que se trata de una profesión asalariada (Dubet, 2011) que se realiza en establecimientos educativos de distintos niveles, básico, medio superior y superior. Asimismo, los profesores, como el resto de los profesionales, son individuos con sus propios intereses, expectativas y preocupaciones sobre su vida personal y laboral. En esta intersección entre lo profesional, lo institucional y lo individual se producen situaciones conflictivas que, bajo ciertas circunstancias, pueden derivar en actuaciones no éticas.

En general, los comportamientos no éticos se definen por oposición a los considerados éticos o aceptables, o bien, se caracterizan y elaboran tipologías; no obstante, es menos frecuente encontrar una definición propiamente dicha. Shamoo y Resnik (2009), por ejemplo, se centran en la distinción entre prácticas no éticas y prácticas ilegales, alegando que hay circunstancias en que se actúa de manera no ética, pero no necesariamente dentro de la ilegalidad y viceversa. Asimismo, puede haber leyes no éticas ante las cuales las personas podrían decidir cambiarlas o no acatarlas apelando a estándares morales o éticos más amplios.

Por su parte, Macrina (2014) caracteriza las "malas conductas" en términos de desviaciones graves de los códigos de ética o de incumplimientos que afectan el desempeño. Según su planteamiento, para que una conducta pueda considerarse mala se requiere que haya una desvia- 
ción significativa de las prácticas aceptadas por la comunidad, así como la intención consciente o imprudente de quien la comete, lo cual debe demostrarse con pruebas contundentes.

Específicamente con respecto a la profesión docente, Martínez (2010) sostiene que un buen profesor tiene que ser un profesional competente y éticamente íntegro. Pero estos dos componentes no siempre van de la mano, aunque se esperaría que así fuera. En la valoración ética de este profesional intervienen tres elementos: su cualificación, sus intenciones y los resultados logrados, a partir de esto se pueden producir diferentes escenarios (Martínez, 2010). Por ejemplo, un maestro puede tener una alta cualificación, buenas intenciones profesionales y lograr buenos resultados, lo cual permitiría sostener que tiene una actuación ética excelente; contrariamente, puede haber otro que tenga una cualificación baja, pero buenas intenciones y buenos resultados, por lo que su actuación ética podría calificarse como accidentalmente buena; por último, puede darse el caso extremo de que el maestro tenga una cualificación baja, malas intenciones y resultados malos, lo que llevaría a tener una actuación ética perversa.

Martínez (2010) plantea varias situaciones a través de la combinación de estos tres elementos, aquí solo incluimos algunas para señalar que, desde esta perspectiva, el análisis de las conductas no éticas se complejiza porque en ellas intervienen los diferentes perfiles profesionales, el contexto y las intenciones de los sujetos. Por si esto fuera poco, en la docencia existen otras fuentes de tensión como resultado de las diferentes relaciones que los profesores mantienen con el alumnado, los colegas, los padres de familia, la institución, e incluso con el currículum (Martínez, 2010).

Martínez (2010: 115) no habla propiamente de conductas no éticas, sino de lo que denomina corrupción profesional, que define como "cualquier acción u omisión que indica que han sido descuidados los bienes internos para dar prioridad a la acumulación de bienes externos, accediendo a estos últimos por una vía distinta a la recta dedicación profesional". Algunos ejemplos de la corrupción en los docentes son:

- Descuidar la formación continua sobre los contenidos disciplinarios o los aspectos didácticos.

- No preparar apropiadamente las clases o incumplir el programa del curso.

- Relacionarse con excesiva familiaridad con los alumnos, a veces, en un intento por ocultar ciertas carencias profesionales.

- No asistir puntualmente a las clases u otros compromisos laborales, ausentarse continuamente anteponiendo distintas excusas y, en general, trabajar haciendo el mínimo esfuerzo, en detrimento de la formación de los estudiantes.

- No mantener el buen comportamiento del alumnado, descuidar a los estudiantes o atribuirles la responsabilidad a otros colegas y no ejercer la autoridad como docente para enfrentar las problemáticas que se suscitan en la relación con el grupo. 
- No revisar adecuadamente los trabajos o exámenes, ni brindar realimentación a los alumnos. También, asignar calificaciones altas que no reflejan el desempeño real, para compensar la desidia y evitarse problemas.

- Introducir contenidos ajenos al currículum oficial o modificar los temas para hacer proselitismo ya sea filosófico, político o religioso, amenazando a los estudiantes que se oponen a estas prácticas.

- Impartir clases extra a los estudiantes sobre los temas del curso para obtener ingresos adicionales.

- Inflar las calificaciones para incrementar el prestigio de la institución y captar más alumnos, o facilitar su ingreso a otros niveles educativos o al mercado laboral.

- Tratar a los tutorados de manera paternalista, brindarles información privilegiada de tipo académico o personal y hacerlos sus protegidos o confidentes, dañando su desarrollo personal.

- Aceptar o recomendar determinados libros y materiales didácticos a cambio de regalos de las editoriales o empresas, ya sea para el uso particular del docente o para la institución.

- Buscar puestos de dirección con el único fin de obtener ventajas personales, como ingresos más altos, prioridad para elegir los grupos y horarios o lograr mayores puntajes en las evaluaciones, descuidando los bienes internos de dicha función.

- Asumir tareas de inspección para evadir la docencia, abusar del poder que se tiene, no apoyar a los profesores en su trabajo o cumplir solo de manera formal con la legislación educativa, atentando con lo establecido en la ley y contra la excelencia profesional.

Para este autor, es importante no confundir la corrupción con los actos criminales o delitos como el acoso, la violación o cualquier otro comportamiento sancionado en el código penal, los cuales deben ser castigados de acuerdo con la ley, con los agravantes de abuso de confianza y de poder (Martínez, 2010).

Finalmente, entre los trabajos sobre los comportamientos no éticos en el profesorado, queremos destacar la propuesta de Aluja y Birke (2004) que distingue entre conductas éticamente inaceptables, que son las acciones "descritas en los códigos, normas u otros y el contravenirlas, está sujeto a una sanción" (2004: 98) y las éticamente cuestionables, que son aquellas que "aún son debatidas y que en consecuencia no se encuentran definidas de manera generalizada en todos los códigos de ética" (2004: 102), y los conflictos de interés, que son "acciones o comportamientos, mediante los cuales se obtiene una ganancia personal de manera abusiva, ya sea con el fin de obtener una mejor posición laboral o un beneficio económico personal" (Macrina, 2000 citado por Aluja, Birke, 2004: 113). Estos autores analizan dichos comportamientos en el ámbito de la investigación científica y la educación superior; sin embargo, algunos pueden aplicarse al 
trabajo docente de otros niveles educativos, especialmente en lo que respecta a los conflictos de interés. Entre los más importantes están:

- Conflictos que involucran a la institución, los directivos y el personal, como aceptar obsequios o beneficios extra; recibir honorarios o compensaciones por algún servicio; favorecer la contratación de familiares o amigos; obstaculizar la posibilidad del empleo a otras personas; recibir pagos múltiples por el mismo trabajo; ser contratado en un lugar, pero terminar trabajando en otro; $y$, en el caso de los directivos, encubrir este tipo de prácticas.

- Conflictos de esfuerzo, consistentes en la realización de múltiples actividades paralelas al empleo principal que terminan por saturar al profesional y disminuyen el buen desempeño.

- Conflictos de conciencia, que ocurren cuando las creencias o ideas del investigador o el profesor, asumidas de manera inflexible, interfieren en sus juicios, su trabajo y, nosotros agregaríamos, en su relación con los estudiantes.

- Conflictos de interés que implican a los estudiantes y al personal académico, en los que interviene la institución; estos incluyen: la apertura de establecimientos educativos con fines personales o políticos; no disponer de una política honesta de mejoramiento del profesorado; implementar políticas que no favorecen la buena formación de los alumnos; utilizar las políticas de manera excluyente para contratar personal; usar o distribuir indebidamente los apoyos o becas; sesgar los procesos de selección de estudiantes; y falsear la información sobre las condiciones institucionales o de programas educativos.

- Conflictos de interés entre mentores y estudiantes. Esta categoría se refiere claramente al contexto de la educación superior, e incluye: el robo de estudiantes, aceptar más tesistas o becarios de los que se puede orientar y asignarse la primera autoría de un artículo utilizando los datos generados por los alumnos. En el caso de los comportamientos no éticos que podrían aplicarse a docentes de la educación básica y media superior están: el uso de los estudiantes para tareas que no les corresponden, el favoritismo, la discriminación y, nosotros agregaríamos, el maltrato (por su condición de vida o por su posición institucional), la atribución de apodos y la indiferencia ante sus necesidades.

La tipología de estos autores es mucho más amplia y abarca otras cuestiones referidas al trabajo científico, pero, como hemos dicho, seleccionamos las que más se acercan a la docencia y, en algunos casos, adaptándolas a lo que hacen los maestros de otros niveles de enseñanza.

\section{Metodología}

El presente artículo se desprende de un proyecto de investigación comparativa más amplio, en el que participan académicos de España, México, Brasil y Argentina; el objetivo es estudiar las 
diferencias entre las experiencias cívicas de los jóvenes en las instituciones educativas y las que tienen como ciudadanos en otros espacios de la vida cotidiana. Aquí presentamos los resultados obtenidos para el caso mexicano y, específicamente, nos enfocamos en el análisis de las conductas éticamente cuestionables y éticamente inaceptables, señaladas por una muestra de estudiantes del nivel medio superior respecto de sus profesores.

La investigación fue de tipo cualitativo y la estrategia metodológica a la que recurrimos fue el grupo focal, el cual se caracteriza por ser un método dinámico que permite:

[...] documentar procesos complejos y variados a través de los cuales se configuran, elaboran y aplican normas y significados grupales [...] los grupos focales no son un sustituto pobre para aquel investigador que, presionado por el tiempo, no puede hacer trabajo etnográfico, sino que constituyen un método importante para abordar estos temas de estudio en sociedades cada vez más privatizadas, que están menos abiertas a la observación" (Bloor et al., 2001: 17) [Traducción propia].

Particularmente, en esta investigación nos interesaba ver tanto la diversidad entre los alumnos como la forma en que planteaban sus ideas, si había consenso entre ellos o si tenían discrepancias significativas y, de ser así, cómo las solventaban. Con este propósito, seleccionamos tres instituciones de distintas modalidades educativas ubicadas en diferentes regiones de la Ciudad de México: un bachillerato general situado en la zona norte, al que denominaremos Plantel 1 y dos bachilleratos universitarios localizados al oriente y sur de la ciudad, que serán los planteles 2 y 3 respectivamente.

\section{El instrumento de investigación}

Los grupos focales pueden aportar información valiosa sobre puntos de vista colectivos, los significados que las personas atribuyen a determinadas cosas, sucesos o acciones, los procesos de evaluación grupales, así como la información que utilizan los sujetos para hacer dichas evaluaciones (Bloor et al., 2001). Para ello, es importante que el investigador tenga claridad en la problemática de estudio, porque de allí se desprenderán los temas a tratar en el grupo focal.

En nuestra investigación, el primer paso fue definir las dimensiones generales que conformarían el guion entre todos los colaboradores del proyecto, con el fin de obtener información comparable para los distintos países e instituciones. En un segundo momento, cada equipo de investigación adecuó el contenido de la guía a las particularidades de sus respectivos contextos. De este modo, dado que el interés era acercarnos a las experiencias cívicas de los jóvenes, tanto al interior de las instituciones educativas como fuera de ellas, se consideraron cuatro aspectos de la participación: en los centros educativos, en la política, en el entorno social, y en las redes y canales tecnológicos; también se incluyó el tema de la transición de la infancia a la adolescencia y las percepciones sobre la diversidad social y cultural. 
La pregunta detonadora planteada a los participantes en los grupos focales fue: "¿Qué opinan ustedes de que actualmente se diga que los jóvenes no tienen interés en contribuir a la solución de los problemas sociales, intervenir en la política o participar en la vida cultural?". La discusión se orientó para cubrir las distintas temáticas previamente establecidas, sin embargo, a la par surgieron otras que no estaban incluidas en el inicio, como las conductas no éticas de los profesores. Los miembros del equipo de investigación decidimos ahondar más en ellas, no solo porque fue una cuestión común entre los tres planteles seleccionados sino, también, por la importancia que tiene en la formación de los estudiantes como ciudadanos y futuros profesionales.

\section{Análisis de la información}

Para el análisis, primero se obtuvo la versión estenográfica de los grupos focales. Posteriormente, se definieron las categorías con base en las seis dimensiones ya señaladas y, utilizando el programa Atlas.ti 7, se separaron y etiquetaron los fragmentos correspondientes a las diferentes categorías en cada uno de los documentos primarios. También se identificaron otras temáticas señalas por los jóvenes y que se salían del guion inicialmente establecido.

La siguiente fase consistió en examinar el contenido de lo expresado en cada grupo focal, a fin de comprender sus elementos característicos y vincularlos con el contexto institucional, local y familiar de los educandos. Por último, se realizó un análisis transversal de los tres grupos focales para observar patrones en las formas de participación, así como problemáticas e intereses comunes entre los participantes.

\section{Los sujetos y el contexto de investigación}

El trabajo empírico se llevó a cabo con estudiantes de nivel medio superior. Cada grupo focal estaba integrado por 10 jóvenes, cinco mujeres y cinco hombres, que cursaban diferentes semestres y cuyas edades variaban entre 15 y 19 años.

Como ya se mencionó, seleccionamos tres planteles educativos del nivel medio superior. En el primero, ubicado en Azcapotzalco, la mayoría de los jóvenes provenían de este mismo municipio, así como de las alcaldías Álvaro Obregón y Miguel Hidalgo de la Ciudad de México. También había otros que vivían en el Estado de México, en demarcaciones como Tultitlán, Naucalpan, Cuautitlán Izcalli y Atizapán de Zaragoza. A los estudiantes, en promedio, les tomaba entre 30 minutos y una hora y media llegar al plantel.

La segunda institución se localiza en Iztapalapa. Los participantes del grupo focal residían en los municipios de Benito Juárez, Iztacalco y, por supuesto, el propio Iztapalapa, así como en Nezahualcóyotl, Chalco y Texcoco, del Estado de México. El tiempo para desplazarse de sus casas a la escuela variaba entre 30 minutos y una hora con 40 minutos.

En estos dos grupos focales, los educandos coincidieron en que en la zona había mucha inseguridad, principalmente robos en el trayecto de los planteles a las paradas del transporte 
público, y situaciones de violencia provocadas por bandas juveniles. Sobre sus respectivas colonias, también reportaron problemas como asaltos, tanto en las casas como a transeúntes, venta de drogas, falta de vigilancia o colusión entre la policía y los delincuentes, pocos espacios de esparcimiento y violencia intrafamiliar.

El tercer plantel seleccionado pertenecía a Xochimilco y los estudiantes hacían un tiempo de traslado entre 15 minutos y una hora. Los municipios de procedencia eran Xochimilco, Coyoacán, Iztapalapa y Tláhuac. Aquí, el principal problema señalado fue la inseguridad alrededor de la escuela. A continuación, analizaremos los comportamientos éticamente cuestionables y éticamente inaceptables identificados por los alumnos.

\section{Conductas éticamente cuestionables en los profesores de bachillerato}

Los profesores realizan numerosas acciones en su quehacer cotidiano docente, muchas de ellas basadas en sus creencias y experiencias previas, por ejemplo, se apoyan en las enseñanzas de sus profesores o bien, valoran una técnica didáctica con base en la eficacia que tiene para ellos, sin que necesariamente reflexionen sobre sus efectos en la formación del alumnado o se pregunten si dicha técnica es congruente con la ética docente. La costumbre, la reproducción de las prácticas y su ponderación, hacen que estas se consagren y se consideren necesarias bajo los principios de: "así se ha hecho siempre" o "así me educaron a mí".

En este apartado analizamos las conductas éticamente cuestionables que, tal como definen Aluja y Birke (2004), son aquellas que no se precisan de manera generalizada en todos los códigos de ética profesional y para las que no siempre hay sanciones específicas. Nos centramos en cinco comportamientos señalados por los participantes de los grupos focales: la desactualización de los métodos de enseñanza, la poca capacidad de diálogo, el desinterés por el aprendizaje, la imposición de temas por parte del profesor y la indiferencia ante situaciones de violencia.

\section{La desactualización de los métodos de enseñanza}

En la revisión que hicimos sobre las investigaciones respecto del "buen profesor", un punto que se destacó fue que, para los estudiantes, los buenos docentes son aquellos que conocen su asignatura, dominan la materia que imparten y se preocupan por estar al día y ampliar sus conocimientos; saben utilizar muchos recursos y estrategias para el aprendizaje, no se limitan a "dar su clase" (Chávez, 2019: 154).

No obstante, en nuestro estudio los jóvenes manifestaron su malestar por la poca innovación de sus maestros durante el proceso de enseñanza. Según su opinión, la mayoría no utiliza técnicas didácticas que promuevan su interés en alguna teoría, concepto o situación problemática. La ausencia de herramientas que logren su motivación y participación es un indicador de la desactualización docente. Los siguientes testimonios sirven de ejemplo: 
[...] hay mucha diferencia, ahora imaginemos una escuela de 1960 y una escuela de ahora, ¿hay diferencia?, sigue siendo el mismo método de enseñanza, asi̋ que digan la nueva reforma estudiantil como la que nos acaban de meter que ya no son parciales ahora son cortes es prácticamente lo mismo, no veo que cambien el método de enseñanza (Estudiante, plantel 1).

[...] yo digo que también sería reformar a los maestros, porque la mayoría de maestros ya tampoco son tan inteligentes [...] sería mejor poner a unos maestros que en verdad estén interesados por enseñar a los alumnos y estén preocupados porque aprendan (Estudiante, plantel 3).

\section{Poca capacidad de diálogo}

Otra cuestión que ha sido señalada en la literatura es la demanda del estudiantado para que los maestros les ofrezcan un trato cordial, una relación que invite al diálogo académico donde todos los integrantes del grupo sean escuchados y puedan opinar, sin que esto reste autoridad al docente. De acuerdo con Caballero-Montañez y Sime-Poma (2016), la disposición al diálogo y para tratar asuntos de interés para los alumnos incide positivamente en el rendimiento académico, en especial cuando se trabaja con adolescentes, porque suelen enfrentar múltiples obstáculos para plantear sus inquietudes y dudas con otros adultos, ya sea en sus casas o en otros contextos.

En ese sentido, podemos decir que la ética profesional se expresa en el quehacer diario del docente, quien con su conocimiento y actitud forma en valores; el respeto por las opiniones de los otros es un valor que se enseña en las prácticas cotidianas. Sin embargo, cuando el maestro no posee el conocimiento, y además no escucha a sus alumnos, su autoridad se desvanece. En los grupos focales este malestar estuvo presente entre los estudiantes, quienes dijeron que algunos profesores no mostraban ni la autoridad ni la disposición para dialogar.

No sabía enseñar. No sabía explicar. Y se enojaba muy rápido, porque si tú necesitabas una explicación de algún tema, ella te decía "un poquito más alto" y luego decía "no me grites". Cuando decías algo mal, su sonrisa como que decía: "estás estúpido" (Estudiante, plantel 1).

[...] si vas con algunos como de sesenta, setenta años te van a decir: "no pues tú estás menso, tú qué sabes de la vida" y no, no te van a dar a expresarte libremente, porque van a pensar que el modo que ellos tienen o la sociedad que les tocó a ellos va a seguir igual y, pues, son otros tiempos [...] (Estudiante, plantel 3).

\section{El desinterés por los que aprenden los alumnos}

Para Hortal (2000), el docente eleva la vida de las personas que se benefician con su trabajo profesional, en este caso los educandos. El profesor que desempeña su labor con ética profesional asume responsablemente la tarea de revisar los avances y dificultades que estos enfrentan a lo largo del curso. Cuando detecta algún problema, como la falta de comprensión de un tema, una 
teoría o un concepto, entonces debe intervenir para que se alcancen los objetivos del curso. Si el maestro evade esta tarea necesaria, su conducta es éticamente cuestionable porque se desentiende del aprendizaje de sus estudiantes y no cumple cabalmente con su deber profesional. Los siguientes extractos dan cuenta de este problema en los jóvenes que participaron en nuestra investigación:

[...] yo digo que la forma de enseñar de los maestros, porque algunos se enfocan en sus métodos de enseñanza, pero no enfocan en lo que en verdad tienen que aprender los alumnos. Por ejemplo, a mí me tocó el caso de que un maestro de literatura me dijo que, o sea, nunca me ha enseñado a hacer ensayos y en los extraordinarios tenía que hacer ensayos, entonces, cómo puedo aprobar ese examen si no me enseñaron eso (Estudiante, plantel 3).

Con el de sociales de segundo semestre que solo te dice que contestes el libro y ya, aunque le pongas ahí: “¿cuándo fue la independencia de México?", y tú le pongas de pura burla:"me comí un burrito”, ni te lo revisa, solamente te pone la palomita y te dice que te vaya bien (Estudiante, plantel 1).

\section{Imposición de temas para la entrega de los trabajos}

Si asumimos que la autonomía es un principio fundamental en todo ser humano, cada persona, sin distinción alguna, debe decidir su credo religioso, su posición política, sus gustos artísticos, su trabajo y su preferencia sexual, entre otros. Un acto ético es aquel que se decide con autonomía y responsabilidad, porque se requiere un juicio valorativo sobre aquello que se hará y sus posibles consecuencias. La autonomía, sostiene Hortal (2000), se fundamenta en el diálogo y la colaboración entre el docente y los alumnos, su objetivo es hacer que estos últimos aprendan a ejercerla en plenitud de derechos, capacidades y responsabilidades.

Para ello, es menester que el maestro haga bien su trabajo, enseñe a los estudiantes a decidir por sí mismos y les dé la confianza de que sus puntos de vista serán respetados, aunque no siempre coincidan con los suyos. No obstante, en el contexto de las clases, esta es una tarea difícil de alcanzar porque el profesor puede verse tentado a utilizar su posición para orientar las opiniones de los educandos o, incluso, imponer determinadas temáticas, condicionando las calificaciones. Al respecto, los jóvenes señalaron lo siguiente:

[...] bueno, con lo de la libertad de expresión, me dejaron un trabajo de historia que era sobre la equidad o igualdad de género. Entonces, yo diría, a las mujeres ya las están protegiendo ¿pero a los hombres? A los hombres los acosan y luego ellos les da vergüenza hablar porque dicen: "no, me van a decir que soy menos hombre o algo así". Entonces, yo le planteé a la maestra, pues voy a enfocarlo en los hombres porque aquí también se vería raro que fuera solo a mujeres y la maestra dijo: "no es el de las mujeres y no sé qué, si los hombres tienen la culpa", y le digo "maestra es mi trabajo", "no y si lo haces así te voy a reprobar (Estudiante, plantel 3).

Diálo@os sobre Educación año 12 | número 23 | julio-diciembre 2021 | ISSN 2007-2171 


\section{La indiferencia ante situaciones de violencia}

Además de enseñar, evaluar los aprendizajes, dar seguimiento y atender las dificultades que se presentan, el profesor tiene entre sus funciones mantener el control del grupo y lograr un clima de respeto y cordialidad entre el estudiantado (Lozano, 2016). Si en la clase surge algún conflicto o si los alumnos se agreden física o verbalmente, este tiene la obligación de intervenir para solucionar el problema y mantener la convivencia pacífica. O bien, si algún estudiante muestra un problema de salud, el maestro debe auxiliarlo, avisar a las autoridades competentes y solicitar la atención médica. Es decir, el docente no puede solucionarlo todo, pero sí le corresponde apoyar al educando y gestionar la ayuda cuando se presentan situaciones de riesgo o violencia, tanto en el salón de clases como en otros espacios institucionales. No obstante, algunos se desentienden ya sea debido al exceso de trabajo o porque creen que no es parte de sus funciones o, incluso, por indolencia.

[...] en el semestre anterior tenía un compañero que a nadie le caía bien, porque siempre se estaba burlando de los demás [...] una vez hablé con una maestra porque él estaba gritando algo así y le dije: "oye, puedes guardar silencio, es que intento hacer mi trabajo" y me empezó a decir de cosas a mí, me empezó a insultar [...] y hablé con una maestra y, pues, no hicieron nada realmente, no, nada más le dijeron: "deja de hacerlo" y ya. Pero, o sea, era un caso que hasta hizo llorar a un compañero y le empezó a decir cosas de su mamá que estaba enferma y se puso a llorar, hasta se puso en depresión el compañero y también me molestó mucho eso (Estudiante, plantel 2).

El maestro, en tanto representante de la autoridad institucional en la clase y como el adulto del grupo, tiene que enfrentar estos incidentes. La insensibilidad o apatía ante este tipo de situaciones es una conducta éticamente cuestionable, porque se pone en peligro la integridad física y emocional de los estudiantes.

\section{Conductas del profesorado éticamente inaceptables}

Este tipo de comportamientos son los que se apartan de las buenas prácticas de un profesional, con base en lo que marcan los códigos $u$ otros instrumentos institucionales y para las que se han establecido sanciones específicas. Aquí incluimos el acoso sexual, así como las actitudes discriminatorias por la situación económica y por la apariencia física de los estudiantes.

Particularmente, el acoso ha sido objeto de múltiples debates en el campo de la ética profesional y se encuentra sancionado en los códigos penales de muchos países, entre ellos México. Para Martínez (2010), esta es una conducta que va más allá de lo éticamente inaceptable, la considera un acto criminal que, en el caso de los docentes, además tiene los cargos de abuso de confianza y de poder. Lo mismo ocurre con la discriminación, tipificada en el Código Penal Federal como parte de los delitos contra la dignidad de las personas (DOF, 2020). 


\section{El acoso sexual}

El acoso sexual es un acto de violencia de género que incluye desde el chantaje y las amenazas sexuales como condición para obtener algo, por ejemplo, un empleo o calificaciones aprobatorias, hasta el uso de bromas sexuales, comentarios denigrantes, insinuaciones, e incluso el contacto físico, para crear un ambiente hostil que interfiere con el desarrollo académico y laboral de las personas (Buchanan et al., 2013). En las instituciones educativas, el acoso sexual puede darse entre los distintos miembros de la comunidad, ya sea de estudiante a estudiante, de profesor a alumno, de profesor a profesor, de directivo a profesor, o de profesor a trabajador administrativo, sin embargo, cuando ocurre de maestro a estudiante las implicaciones pueden ser profundas, no solo porque el primero tiene la responsabilidad ética de crear y mantener un ambiente seguro y respetuoso en la clase, sino por la situación de vulnerabilidad en la que se encuentran los segundos, especialmente cuando se trata de menores de edad.

Algunos de los jóvenes que participaron en nuestra investigación dijeron que en determinados momentos se sintieron hostigados por sus profesores; ante ello, sus reacciones fueron diversas, desde los que sintieron miedo, ira o impotencia hasta los que buscaron caminos para dar cauce a este problema.

Bueno, por ejemplo, el año pasado, un maestro, seguramente muchos lo conocen por eso, estábamos todos sentados en la banca, bueno, cada uno en su lugar y llegaba y te hacía así [hace un gesto]. Y pues, una vez iba entrando al salón y a todos les estaba picando la panza, el profesor a ellos y, pues yo venía enojada ese día y, pues, no me hizo nada, porque creo que casi lo golpeo (Estudiante, plantel 3 ).

Me pasó una vez que yo estaba afuera en el parque con mi amiga y llegó un mensaje y nos empezó a hablar y mi amiga le contestaba muy feo (Estudiante, plantel 1).

En las modalidades educativas en las que desarrollamos nuestra investigación, se cuenta con normativas en las que el acoso está tipificado como un acto de violencia que debe ser sancionado. Por ejemplo, el Colegio de Bachilleres, además del código de ética, dispone de un protocolo para la recepción y atención de este tipo de denuncias (ColBach, 2019a, 2019b). Por su parte, los bachilleratos de la UNAM se acogen a la Guía de Derechos y Deberes de los Estudiantes (DDU-UNAM, 2016) y al Protocolo para la Atención de Casos de Violencia de Género (Abogado General-UNAM, 2019). El problema es que estos lineamientos no siempre se conocen y tampoco se implementan estrategias para que estudiantes, profesores y directivos sepan cuáles son sus derechos o las sanciones a las que son acreedores en caso de que los infrinjan.

\section{Discriminación por la situación económica}

De acuerdo con Cortina (2017), el desprecio a las personas desposeídas o de escasos recursos ha sido una constante a lo largo de la historia de la humanidad, independientemente del grupo al que pertenezcan, migrante pobre, refugiado pobre, homosexual pobre, etcétera.

Diálo@os sobre Educación año 12 | número 23 | julio-diciembre 2021 | ISSN 2007-2171 
Es el pobre, el áporos, el que molesta, incluso el de la propia familia, porque se vive al pariente pobre como una vergüenza que no conviene airear, mientras que es un placer presumir al pariente triunfador, bien situado en el mundo académico, político, artístico o en el de los negocios. Es la fobia hacia el pobre la que lleva a rechazar a las personas, a las razas y a aquellas etnias que habitualmente no tienen recursos y, por tanto, no pueden ofrecer nada, o parece que no pueden hacerlo (Cortina, 2017: 21).

El desdén hacia el pobre se traduce en acciones y conductas concretas como la exclusión, la desconfianza, la humillación o la indiferencia. Los estudiantes de nuestro estudio denunciaron este tipo de maltrato en sus escuelas, dado que muchos de ellos pertenecen a familias de bajos ingresos que habitan en zonas socialmente desfavorecidas, lo que provoca alerta en las autoridades escolares y el profesorado. Por ejemplo, en un plantel se introdujo la medida de revisar cuidadosamente el interior de las mochilas del alumnado:

Siento que nos tratan como si fuéramos gente mala, o sea, en otras escuelas, nada más les dicen pásate con tu mochila, pero aquí es como que te revisan hasta los calzones (Estudiante, plantel 1).

En esta escuela, la desconfianza hacia los jóvenes fue más allá, ya que las medidas se fueron endureciendo y sin previo aviso.

A mí me molestó cuando dejamos de pasar con la pura credencial y nos pidieron la tira [de materias], porque yo ese día tenía un examen y no pude presentarlo porque había dejado mi tira en mi casa y lo cambiaron de repente (Estudiante, plantel 1).

Otros denunciaron el rechazo hacia los estudiantes con tatuajes y perforaciones, a quienes se les tiende asociar con conductas antisociales o delictivas porque no corresponden con la representación, dominante en las instituciones educativas, de lo que significa ser "un buen alumno", es decir, persona de clase media, arreglado de acuerdo con las convenciones adultas (camisa y pantalón formal, zapatos de vestir, sin tatuajes y con cabello corto). Sobre ello, los jóvenes comentaron:

Yo también digo que hay discriminación a las personas con tatuajes y perforaciones, por decir, si te tatúas ya no te aceptan, donde pues, yo creo que un tatuaje no es una discapacidad para hacer lo que te piden (Estudiante, plantel 2).

La igualdad y la no discriminación son dos principios fundamentales del Código de ética y de la Guía de derechos y deberes de los estudiantes de la UNAM, a partir de los cuales se proscribe el trato desigual a cualquier miembro de la comunidad, por razones de género, origen étnico 
o nacional, religión, edad, estado civil, condición social, laboral o de salud, opiniones personales y orientación o preferencia sexual (DDU-UNAM, 2016; Gaceta UNAM, 2015). Estos mismos principios están contenidos en el Código de Conducta del Colegio de Bachilleres (ColBach, 2019a), de manera que cuando los profesores discriminan a sus alumnos están cometiendo una conducta éticamente inaceptable.

\section{Discriminación por la apariencia física}

Históricamente, el sexo anatómico ha sido utilizado para orientar el comportamiento sexual de hombres y mujeres, bajo el supuesto de que lo "normal" es que haya una plena correspondencia entre lo físico y la sexualidad (Escobar, 2007). Esto se expresa en formas de ser y de hacer que se esperan de los sujetos en los diferentes ámbitos de su vida. Las personas que no cumplen con este estándar son estigmatizadas, discriminadas, agredidas física o verbalmente y excluidas, de manera que la cultura heterosexista continúa siendo un bien altamente valorado en gran parte de la sociedad.

En las instituciones educativas, el denominado "bullying homofóbico" es un problema persistente, no solo en el trato entre los estudiantes sino entre el profesorado y otros agentes educativos (Cornejo, 2018). De este modo, se hacen grandes esfuerzos para que los alumnos asuman los valores y comportamientos heterosexuales, así como para identificar y hostigar a los que se salen de la norma.

En nuestra investigación, los estudiantes denunciaron este tipo de prácticas en algunos de sus maestros.

[...] yo tenía un maestro que a los hombres les decía: "córtate el cabello porque pareces niña y ya no te voy a dejar entrar, si sigues con el cabello largo". Y a mí me molestaba mucho, pero nunca hicimos nada, o sea, no sé, me molestaba mucho que el maestro decía "o eres gay o algo así, te decía y los discriminaba (Estudiante, plantel 2).

Además, los jóvenes apuntaron hacia las consecuencias que esto puede tener en la vida de los sujetos:

[...] si es una persona que no se lo toma muy a pecho, pues dice: "ay, locos", pero si es una persona que realmente piensa lo que los demás le dicen, le están poniendo inseguridades a él como persona y, de hecho, es una forma muy mala como de hacer que los excluyan de los grupos [...] (Estudiante, plantel 2).

Más allá de estos efectos, como ya señalamos, la discriminación es una conducta proscrita en la normatividad tanto del Colegio de Bachilleres como de la UNAM. Además, el Código Penal Federal de nuestro país (DOF, 24/01/2020) establece que la negación y restricción de los ser- 
vicios educativos por cualquier rasgo individual, práctica o pertenencia a un colectivo, es un comportamiento discriminatorio que atenta contra los derechos y libertades de las personas. De este modo, podríamos decir que los docentes o cualquier miembro de la comunidad, que realice o fomente este tipo de acciones, está cometiendo un delito.

\section{Consideraciones finales}

Uno de los supuestos que apuntaló esta investigación, sostiene que en las instituciones educativas los valores se transmiten no solo por medio de los contenidos formales, sino sobre todo a través de la actuación de los sujetos; particularmente en el caso de los profesores, a través de lo que dicen y hacen en las clases, así como del trato y las relaciones que entablan con sus alumnos.

Los resultados obtenidos con los estudiantes de tres bachilleratos de la Ciudad de México nos permitieron observar diversas situaciones, donde el comportamiento y trabajo de los profesores se aleja de los principios de la ética profesional. Las conductas éticamente cuestionables están directamente relacionadas con los bienes intrínsecos de la docencia, es decir, con aquello que le da sentido a la profesión y que, como sostiene Hortal (2000), permiten que contribuya a hacer la vida más humana. La desactualización de los métodos de enseñanza, el desinterés por lo que aprenden sus alumnos y la imposición de los temas, son cuestiones que repercuten en la formación académica del estudiantado, en los conocimientos y habilidades que se supone debe adquirir en el bachillerato y que, a la postre, pueden incidir en sus oportunidades laborales o educativas si decide cursar el nivel superior.

Es decir, no preparar bien las clases, no abordar adecuadamente los contenidos de los cursos o no retroalimentar ni revisar los trabajos y exámenes son comportamientos éticamente cuestionables que no solo dañan la imagen del profesor o de la institución educativa, sino que pueden tener consecuencias importantes en las vidas de los educandos. Por supuesto, los docentes no son los únicos responsables, pero indudablemente ocupan un lugar muy importante dado su papel de mediadores entre la familia y la sociedad, los conocimientos establecidos y los nuevos saberes, así como entre la infancia/juventud y la edad adulta (Martínez, 2010).

Otros comportamientos éticamente cuestionables señalados por los educandos fueron la poca capacidad de diálogo y la indiferencia ante situaciones de violencia. Si bien estas no constituyen habilidades exclusivas del campo pedagógico, son fundamentales en una profesión cuyas posibilidades de éxito dependen en buena medida tanto de las capacidades comunicativas de los sujetos como de la relación que logren construir entre ellos. Como ya señalaban Caballero-Montañez y Sime-Poma (2016), la capacidad de diálogo de los docentes y su disposición para abordar cuestiones de interés para sus alumnos son factores que también intervienen en el rendimiento académico, además del manejo de los contenidos, la utilización de estrategias didácticas y técnicas de evaluación eficientes. De este modo, es difícil pensar en un buen profesor 
que no quiera escuchar a sus alumnos, que desacredite de antemano sus ideas, que no se ocupe de mantener el respeto y la cordialidad entre los miembros de su clase, o que no le interese gestionar la ayuda cuando uno de ellos se encuentra en una situación de riesgo.

Con respecto a lo éticamente inaceptable, los alumnos de bachillerato señalaron principalmente la discriminación por la situación económica o por la apariencia física y el acoso sexual. Al respecto, coincidimos con Martínez (2010) en que este tipo de acciones constituyen delitos que deben ser sancionados con base en lo que establece el Código Penal Federal de nuestro país, es decir, están más allá de la ética profesional, porque atentan contra la dignidad física y emocional de los individuos. En las instituciones educativas, el problema es aún más complejo porque los estudiantes, como resultado de su edad, inexperiencia o, incluso, del lugar que ocupan en la dinámica escolar, se encuentran en una situación vulnerable.

Particularmente, la violencia sexual había sido un tema tabú en las instituciones educativas dado que no existían los mecanismos para sancionar estas prácticas y atender a las víctimas, lo cual a su vez contribuía a la cultura de la negación individual, institucional y social (Barreto, 2017). Sin embargo, hace un par de años, el movimiento de mujeres contra la violencia sexual, iniciado en algunas universidades y escuelas de educación media superior de la Ciudad de México, en el contexto de otros movimientos de denuncia a nivel internacional como el \#MeToo y que pronto se replicó en varios estados de nuestro país, puso de manifiesto no solo la profundidad del problema, sino la poca eficacia de los procesos institucionales para proteger a las y los educandos de las agresiones de las que eran objeto, tanto por parte del profesorado como de otros miembros de la comunidad.

El problema de la discriminación aparenta estar menos visible, pero eso no significa que no esté presente, en especial, cuando se trata de colectivos vulnerables como los adolescentes, los indígenas, las mujeres y las personas con discapacidad. El rechazo, las burlas, la asignación de apodos, el maltrato o la negación de cierto servicio son algunas de las prácticas más comunes, las cuales muchas veces pasan desapercibidas porque forman parte de un patrón que se extiende desde la familia hasta las instituciones públicas, incluyendo por supuesto a la escuela (Solís, 2017).

De este modo, es fundamental que las instituciones educativas mejoren sus mecanismos para detectar todas estas conductas, tanto las éticamente cuestionables como las éticamente inaceptables, brindando certeza a los alumnos de que sus denuncias serán atendidas con la debida protección a su persona. Finalmente, consideramos que lo anterior es insuficiente si no tratamos de cambiar las ideas que están en la base de estos comportamientos y que, en el caso de los docentes, algunas atañen a la cultura profesional, pero otras apuntan a lo que somos como sociedad, a los mínimos éticos (Cortina, 2000) que debemos respetar para salvaguardar el bienestar individual y colectivo. 


\section{Referencias}

Abogado General-UNAM (2019). Protocolo para la atención de casos de violencia de género. México: UNAM.

http://www.ibt.unam.mx/computo/pdfs/protocolo-de-actuacion-en-casos-de-violencia-de-genero-2019.pdf

Aluja, M.; A. Birke (2004). Panorama general sobre los principios éticos aplicables a la investigación científica y la educación superior. En Aluja, M. y Birke, A. (coords.). El papel de la ética en la investigación científica y la educación superior. México: Fondo de Cultura Económica, 87-143.

Angulo, G. (2012). Las concepciones sobre el docente o diferentes maneras de concebir el ejercicio de la docencia. Revista de Investigación, 36(15), 11-31.

http://ridum.umanizales.edu.co:8080/xmlui/handle/6789/2781

Barreto, M. (2017). Violencia de género y denuncia pública en la universidad. Revista Mexicana de Sociología, 79(2), 261-286.

http://revistamexicanadesociologia.unam.mx/ index.php/rms/article/view/57663/51120

Berger, P.; T. Luckmann (1991). La construcción social de la realidad. Argentina: Amorrortu.

Bloor, M.; J. Frankland; M. Thomas; K. Robson (2001). Focus Group in Social Research. Londres: Sage publications.

Buchanan, N.; B. Bluestein; A. Nappa; K. Woods; M. Depatie (2013). Exploring Gender Differences in Body Image, Eating Pathology, and Sexual Harassment. Body Image, (10), 352-360. http://isiarticles.com/bundles/Article/pre/pdf/37501.pdf

Caballero-Montañez, R.; L. Sime-Poma (2016)."Buen o buena docente"desde la perspectiva de estudiantes que han egresado de educación secundaria. RevistaElectrónicaEducare, 20(3), 1-23. https://www.scielo.sa.cr/scielo.php?script=sci arttext\&pid=S1409-42582016000300075

Casillas, S. (2006). Percepciones de alumnos y profesores sobre el "buen" docente universitario. Papeles Salmantinos de Educación (7), 271-282. https://core.ac.uk/download/pdf/50604748.pdf

Colegio de Bachilleres (2019a). Código de conducta del Colegio de Bachilleres. México: ColBachSEP. https://buzon.cbachilleres.edu.mx/Docs/Codigo Conducta 2019.pdf

Colegio de Bachilleres (2019b). Protocolo para la recepción y atención de denuncias sobre incumplimientos al Código de ética, a las Reglas de integridad o al Código de conducta del Colegio de Bachilleres, así como por hostigamiento sexual, acoso sexual y violación a la igualdad y no discriminación. México: ColBach-SEP.

https://buzon.cbachilleres.edu.mx/Docs/Protocolo Procedimiento 2019.pdf

Cornejo, J. (2018). Discriminación y violencia homofóbica en el sistema escolar: estrategias de prevención manejo y combate. Revista Brasileira de Educação, (23), 1-24.

http://www.scielo.br/pdf/rbedu/v23/1809-449X-rbedu-23-e230031.pdf

Cortez, K.; V. Fuentes; I. Villablanca; C. Guzmán (2013). Creencias docentes de profesores ejemplares y su incidencia en las prácticas pedagógicas. Estudios Pedagógicos, XXXIX(2), 97-113. https://scielo.conicyt.cl/scielo.php?pid=S071807052013000200007\&script =sci arttext\&tlng=en 
Cortina A. (2000). Ética mínima. Introducción a la filosofía práctica. Madrid: Tecnos.

Cortina, A. (2017). Aporofobia, el rechazo al pobre. Un desafío para la democracia. Barcelona: Paidós.

Chávez, G. (2019). Conocimiento, didáctica y empatía: rasgos de los profesores de excelencia según estudiantes universitarios. En Hirsch, A.; J. Pérez-Castro (coords.). Ética profesional y responsabilidad social universitaria: experiencias institucionales. México: UNAM-IISUE, 149164.

Defensoría de los Derechos Universitarios-UNAM (2016). Guía de derechos y deberes de los estudiantes de la UNAM. México: UNAM.

https://archivos.juridicas.unam.mx/www/bjv/libros/10/4603/2.pdf

Diario Oficial de la Federación (2020). Código penal federal. Última reforma publicada DOF 24-012020. México: Secretaría de Gobernación.

https://docs.mexico.justia.com/ federales/codigo-penal-federal.pdf

Díaz Barriga, A. (2006). La educación en valores: Avatares del currículum formal oculto y los temas transversales. Revista Electrónica de Investigación Educativa, 8(1), 1-15. http://redie.uabc.mx/vol8no1/contenidodiazbarriga2.html

Durkheim, E. (2000). Educación y sociología. Barcelona: Península.

Escobar, J. (2007). Diversidad sexual y exclusión. Revista Colombiana de Bioética, 2(2), 77-94. https://www.redalyc.org/pdf/1892/189217250004.pdf

Gaceta UNAM (2015). Código de ética de la Universidad Nacional Autónoma de México. México: UNAM. http://www.ifc.unam.mx/pdf/codigo-etica-unam.pdf

Gutiérrez, C. (2012). La representación del buen maestro: un acercamiento a partir del habitus de los formadores de docentes. En Mireles, O. (coord.). Representaciones sociales: emociones, significados y prácticas en la educación superior. México: UNAM-IISUE, 85-125.

Hamer, A. (2015). La percepción del buen profesor en alumnos de nuevo ingreso a la enseñanza universitaria: el caso de ETEA (Córdova). Revista Complutense de Educación, 26(2), 227-240. https://core.ac.uk/download/pdf/38821462.pdf

Hortal, A. (2000). Docencia. En Cortina, A. y Conill, J. (direct.). 10 palabras clave en ética de las profesiones. Navarra: Verbo Divino, 55-78.

Jackson, P. (1992). La vida en las aulas. Madrid: Morata.

Larrosa, J. (2006). Sobre la experiencia. Educación y Pedagogía (18), 43-51.

https://revistas.udea.edu.co/index.php/revistaeyp/article/view/19065

Lozano, I. (2016). Representaciones sociales de los profesores de secundaria sobre su formación y práctica docente. Revista Ciencias de la Educación, 26(47), 61-78.

http://servicio.bc.uc.edu.ve/educacion/revista/47/art04.pdf

Martínez, E. (2010). Ética profesional de los profesores. Bilbao: Desclée De Brouwer. 
Mas, O. (2012). Las competencias del docente universitario: la percepción del alumno, de los expertos y del propio protagonista. Revista de Docencia Universitaria, 10(2), 299-318. https://dialnet.unirioja.es/servlet/articulo?codigo $=4021101$

Navia, C. (2019). Aproximaciones conceptuales en torno al buen docente en educación superior. Hirsch, A.; J. Pérez-Castro (coords.). Ética profesional y responsabilidad social universitaria: experiencias institucionales. México: UNAM-IISUE, 181-197.

Navia, C.; A. Hirsch (2015). Dimensiones y rasgos sobre la excelencia del profesorado en instituciones formadoras de docentes en dos países de América Latina. Edetania (48), 117-130. https://revistas.ucv.es/index.php/Edetania/article/view/41

Shamoo, A.; D. Resnik (2009). Responsible Conduct of Research. Nueva York: Oxford University Press.

Solís, P. (2017). Discriminación estructural y desigualdad social. México: CONAPRED. 